\title{
Textile Azo Dyes; Significance, Ecological, Health, and Safety issues
}

\author{
S.M.Imtiazuddin \\ (Popular Fabrics) and Anwer Tiki (AVM Chemicals) \\ Karachi, Pakistan \\ Corresponding Author's Email:simtiazuddin@yahoo.com
}

\begin{abstract}
:
In the textile industry, synthetic aromatic dyes are commonly used for dye fabrication. The largest group of synthetic dyes is Azo dyes, highly water-soluble and the main counterpart of the textile industry. It is composed of aromatic rings that are highly persistent. Environmental protection and product safety measures are becoming increasingly important during the purchase of textiles products due to the dynamic nature of the debate and more significant consumer concern. It is essential to develop awareness regarding the use of azo dyes, their significance in the dyeing industry, and health-related issues on a more factual basis. This review article provides background notes on the German Consumer Goods Ordinance, coupled with a list of the amines and dyestuffs involved. Evidence is also provided about the test methods used for textiles and a summary of national regulations relating to azo dyes.
\end{abstract}

Keywords: textile industry, Azo dyes, awareness

\section{INTRODUCTION}

\subsection{Significance of Azo dyes}

Several industries like food, textile, leather, pharma, printing, and cosmetic industry commonly used synthetic colors, consisting of 60 to $70 \%$ of azo dyes. Azo dyes are the central part of the above industries consist of two $\mathrm{N}$ atoms linked to each other and chemicals used in their synthesis referred to as fragrant amines and are primarily of yellow, red, and brown colors. Usually, these dyes are not directly applied to the fabrics but erected inside the fibers. For this purpose, fibers soaked in an element of the dye and other components of the dye infused in the fiber produced azo dyes; in this way, very fast and effective color developed with the generation of hazardous dye wastewater. The fast and effective color of the azo dye is due to the aromatic compounds. Their synthesis is straightforward and cheap. These compounds are readily available and adjusted easily according to the requirement, followed by less energy required for the whole dye fabrication process.

\subsection{Toxicological Health Background of Azo Dyes}

The discharge of azo dye effluent as wastewater from several industries poses unfavorably on running streams, agricultural lands, aquatic life, and disturbed integrity of the ecosystem. The whole marine biota of the discharged place of dye wastewater becomes under stress, mainly related to increased chemical oxygen demand (COD), which adversely affects biological oxygen demand (BOD) as azo dyes are persistent, not readily degradable under natural conditions, and by simple wastewater treatment method. These dyes are synthesized by the diazotization of aromatic amines, followed by coupling to a further aromatic compound (known as the coupling component). This results in the formation of the so-called azo grouptwo nitrogen atoms joined by a double bond as shown in equation

$$
\mathrm{A}-\mathrm{N}=\mathrm{N} \text { - B (Azo Dye) ------------ A - } \mathrm{NH}_{2}+\mathrm{B} \text {-- } \mathrm{NH}_{2} \text { (Amines) }
$$

These dyes wastewater recognized as harmful to the human urinary bladder and found toxic during laboratory testing on animals. Azo dyes can also be metabolically cleaved by bacteria in the human digestive tract or by the enzymatic reduction in some organs, as reported by Puvaneswari et al.[1] who observed biodegradation of azo groups (-N=N-) under mild conditions through two Pseudomonas strains. They also reported toxicity of dye effluents on plants, fishes, and the environment with probable bioremediation of these dyes. Several studies carried out with textile workers handling benzidine dyes showed the presence of traces of free benzidine in the urine. MAK amines released in the human organism from azo dyestuffs can have a carcinogenic effect there. Epidemiological studies describe an increased incidence of bladder carcinoma among painters and dye factory workers who never contacted free MAK amines related to the azo dyes. It should be emphasized here that benzidine dyes and “MAK- dyes” (Maximate Arbeitsplatz -Konzeentration) have a carcinogenic effect under sufficient exposure, i.e., when these dyes enter the human organism as a result of improper handling or low occupational safety standards.

\subsection{Environmental Impact of Azo Dyes}

The textile industry is indispensable globally; it is also responsible for damaging the environment regarding its waste, including solid, liquid, and gaseous emissions. Dye wastewater is the most environmentally damaging effluent of the textile industry and is classified as the most polluting part of the industrial sector [2]. Since the volume generated as well as its composition displayed damaging effect particulary to running bodies. The dyestuff lost through the process of the textile industry poses a significant problem in wastewater management, while the concentration of Azo dye in textile effluent 
reaches to 400 to 500 ppm.It has been observed through the dyeing process that the environmental losses is now recognized as high as $50 \%$ a dye to the dye wastewater contaminant while first a minimal amount of Azodye was reported in the water $(<1 \mathrm{ppm})$ as they are highly visibl [3]. Colorant material decreasing light penetration in water bodies ultimately decreases photosynthetic activity, generating oxygen deficiency and de-regulating the biological cycles of aquatic biota [3]. Several Azo dyes are also highly toxic to the ecology and mutagens, indicating they showed chronic effects upon organisms, depending on the exposure time and Azo dye concentration. For example, dye effluent has been connected to growth declining, neurosensory damage, metabolic stress and sad demise in fish, and development and yield in plants. Contamination, therefore, limits downstream, human water uses such as recreation, drinking, fishing, and irrigation.

\subsection{The German consumer Goods Ordinance}

The recent regulations concerning eco-friendly textile products prohibited the promotion of textiles dyed-through azo dyes accomplished of reductively excruciating toxic aromatic amines. Execution of the endorsements of the MAK (maximale arbeitsplatz -konzentration) committee and the” Technical Rules for Hazardous Substances” TRGS 614 not to use dyestuffs based on MAK amines. The workplace protection rules of the Hazardous Substances Law and corresponding EU Directive should be implemented before dye factory workers enter to their workplace as health risks associated with inhalation of dust-forming “ MAK dyes” or from direct skin contact with these dyes where they are still in use. The dyes molecule migrated from the workers' skin when they started their work and penetrated the inside body. This risk is also related to where babies or infants suk on textiles or soft toys so that traces of the dye can enter the body with the salvia.

\subsection{EU Restricted Aromatic Amines}

Scientific confirmation on the carcinogenicity of all 24 aromatic amines is listed in the German Consumer Goods Ordinance. All are also listed in Group lll of the MAK list under Category 1 and 2. ( Attachment A)

\begin{tabular}{|c|c|c|c|}
\hline S.No & Aromatic-Amines & CAS No & MAK Group lll under \\
\hline 1. & Benzidine & $92-87-5$ & Category 1 \\
\hline 2. & 4-aminodipenyl & $92-67-1$ & Category 1 \\
\hline 3. & 4-chloro-o-toludine & $95-69-2$ & Category 1 \\
\hline 4. & 2-naphthylamine & $91-59-8$ & Caterory 1 \\
\hline 5. & o-aminoazotoluene & $97-56-3$ & Category 2 \\
\hline 6. & 4-chloroaniline & $106-47-8$ & Category 2 \\
\hline 7. & p-cresidne & $120-71-8$ & Category 2 \\
\hline 8. & 2-amino-4-nitrotoluene & $99-55-8$ & Category 2 \\
\hline 9. & 4-methoxy-m-phenylenediamine & $615-05-4$ & Category 2 \\
\hline 10. & 3,3-dichlorobenzidine & $91-94-1$ & Category 2 \\
\hline 11. & 3,3-dimethoxybenzidine[3,3-dianisidine] & $119-90-4$ & Category 2 \\
\hline 12. & 3,3-dimethyl-4,4-diaminodiphenlymethane & 838-88-0 & Category 2 \\
\hline 13. & 3,3-dimethylbenzidine[o-toluidine] & $119-93-7$ & Category 2 \\
\hline 14 & 4,4-diaminodiphenylmethane & 101-77-9 & Category 2 \\
\hline 15. & 4,4-methylene-bis-(2-chloroanaline) & $101-14-4$ & Category 2 \\
\hline 16. & 4,4-oxydiniline & 101-80-4 & Category 2 \\
\hline 17. & 4.4-thiodianiline & 139-65-1 & Category 2 \\
\hline 18. & 2,4.5-trimethylanaline & $137-17-7$ & Category 2 \\
\hline 19. & 2,4-toluenediamine & $95-80-7$ & Category 2 \\
\hline 20. & o-toluidine & $95-53-4$ & Category 2 \\
\hline 21. & 2-methoxyaniline & $90-01-0$ & Category 2 \\
\hline 22. & 2,4-xylidine & $95-68-1$ & Category 2 \\
\hline 23. & 2,6-xylidine & 87-62-7 & Category 2 \\
\hline 24. & 4-aminoazobenzene & 60-09-03 & Category 2 \\
\hline
\end{tabular}

The Oeko-Tex laboratories test for compliance to this requirement during the certification procedure. Since autumn 1997, Oeko-Tex laboratories only apply the German Consumer Goods Ordinance (No. 82.02-2/-4/-9 in the Official Archives of Testing Methods according to 64 LFGB), as do the Government testing agencies. It indicates that the azo dyestuffs prohibited in the production of textiles fabrics, by the (legally binding ) German Consumer Goods Ordinance, the later EU Directive 2002/61/EC, now adopted to Annex XVII of REACH by Commission Regulation (EC) No.552/2009 may also not be used produce Oeko-Tex supportable textiles.

However, the Oeko-Tex Association goes slightly beyond the statutory requirements in two points. 
Pakistan Journal of Chemistry 2020

1. A prohibited azo dye is deemed to have been used when more significant than $20 \mathrm{mg}$ MAK amine $/ \mathrm{kg}$ textile is detectable. The REACH regulation sets the acceptable limit at $30 \mathrm{mg} / \mathrm{kg}$.

2. As well as prohibiting azo dyestuffs which can be cleaved to release one of the 22 amines listed in the REACH regulation, the Oeko-Tex Standard100 additionally prohibits dyestuffs that can release 2,4-xylidine or 2,6-xylidine.

\section{FINDING SOLUTIONS}

\subsection{Harmonization of Environmental Standards}

Harmonization of environmental standards appeals as a way to help in solving valid environmental objectives worldwide because;

1. Environmental issues often transgress national borders and are of concern to the people of even disparate and distant nations.

2. Different imposters standards can elevate exporters manufacturing expenses, as different methods are required of diverse standards.

3. Protection methods should be applied to maintain the environmental standards.

4. Harmonizing effluent contamination limitations from dyeing factories could help mitigate the environmental issues associated with Azo dyes and other dyes. However, since the environment in each country is not standardized, harmonization can lead to inefficiency related to dye discharge from dyeing factories.

5. Every environment has a different absorptive capacity for water pollutants.

6. The cost required to remove dye pollution differs between countries.

7. Willingness to invest in a healthier environment at personal expense differs from country to country, for example, concerning the degree of local poverty.

\subsection{International controls}

Several countries have specific regulations relating to certain azo dyes and hazardous aromatic amines. In the European Union (EU), 22 aromatic amines derived from certain azo dyes are restricted in articles that may come into direct and prolonged contact with the human skin or oral cavity. The maximum total concentration for all of the aromatic amines is 30 $\mathrm{mg} / \mathrm{kg}$.[4].

In China, the limit for aromatic amines in leather and fur products is 30mg/kg (the Chinese standard is GB 20400-2006, Leather and Fur - Limit of Harmful Matter) [5].

Decomposable carcinogenic aromatic amines are banned in any apparel, decoration textiles, and household textiles placed in China's market. The Chinese standard for textiles is GB 18401-2010 National General Safety Technical Code for Textile Products [6]. In Japan, the 22 aromatic amines restricted in Europe are listed in a voluntary standard. The voluntary standard was developed by the Japan Textile Federation (JTF) and the Japan Leather Industry Association (JLIA). Compliance with the standard may be demonstrated by providing a certificate of analysis or self-declaration [7] Importation of textiles into Japan must be accompanied by test reports, certification documentation (that certain azo dyes have not been used), and information on the manufacturing facility [8]. The introduction of textiles or leather articles containing benzidine-based dyes is proposed to be restricted in the United States. Access to these dyes for home use is not permitted [9,10]. No regulations restrict the supply of textiles dyed with benzidine-based dyes in Canada; however, the use of such dyes has not been detected. In several international jurisdictions, benzidine-based dyes are banned for use in cosmetics.

\subsection{Form of the proposed regulation}

The wording for any possible future regulation has not yet been finalized; however, it is likely to be similar to the key elements of the EU requirements set out in Regulation (EC) No 1907/2006 [11]. Under the EU Regulation, azo dyes that by reductive cleavage of one or more azo groups may release one or more of 22 aromatic amines in detectable concentrations, i.e., above $30 \mathrm{mg} / \mathrm{kg}$, in the dye parts. These must not be used in textile and leather articles that may come into direct and prolonged contact with the human skin or oral cavity [12]

\section{CONCLUSION}

It was concluded that the azo dyes are water-soluble dyes posed impact on human when come in contact through skin or oral inhalation. Several countries imposed banned to certain types of azo dyes to avoid the toxicity to ecosystem

\section{CONFLICTS OF INTEREST}

The authors declare no conflict of interest.

\section{ACKNOWLEDGMENT}

The Author is very thankful to the administration of (Popular Fabrics) and Anwer Tiki (AVM Chemicals) for providing support during my Ph.D thesis.

\section{REFERENCES}


1. Puvaneswari, N., Muthukrishnan, J., \& Gunasekaran, P. (2006). Toxicity assessment and microbial degradation of azo dyes.

2. F.M.D.Chequer et al. (2003). Textile dyes: Dyeing Process and Environmental Impact.

3. K.T.Chung (1983). Mutal Res.114(3):269-81.

4. Apostal, L.C.,Pereira,L.,Pereira,R., Gavriloscu, M., Alves, M.M. (2012) Biodegradation DOI: 10. 1007/s 10532012-9548-7.

5. http://eur-lex.europa.eu/LexUriServ/LexUriServ.do?uri=OJ:L:2009:164:0007:0031:en:PDF

6. https://www.iaaqaservices.bureauveritas.com/reach-ccr/regulation_updates/59737.html

7. http://www.intertek.com/textiles/gb-18401/

8. http://www.gmn.hkpc.org/en_newsletter_details.asp?id=62

9. http://www.cti-cert.com/en/news/news de.aspx?id=3707

10. National Industrial Chemical Notification and Assessment Scheme, 6 June (2013), Inventory Multi-Tiered Assessment and Prioritisation Human Health Tier II Assessment for Benzidine-Based Dyes, available:

11. http://www.nicnas.gov.au/chemical-information/imap-assessments/imap-group-assessmentreport?assessment_id= 523.

12. Regulation EC $1907 / 2006$ is available online. http://eur-lex.europa.eu/legalcontent/EN/TXT/PDF/?uri=CELEX:32006R1907\&from=enPuvaneswari 